\section{MedíEal Seiener}

pISSN 2321-7359; eISSN 2321-7367

To Cite:

Alobaida BA, Alayed FA, Alrudayni AK, Alzabadin RA, Aldera SA, Alrajhi NI, Alfrayan MI, Almassari AK, Alrakaf FA, Alotaibi FZ. Assessment of otolaryngology knowledge among primary care providers in Saudi Arabia. Medical Science, 2022, 26, ms14e2034. doi: https://doi.org/10.54905/disssi/v26i119/ms14e2034

\section{Author Affiliation:}

IImam Mohammad Ibn Saud Islamic University, College of Medicine (IMSIU), Riyadh, Kingdom of Saudi Arabia

2Department of otolaryngology, Imam Mohammad Ibn Saud Islamic University, College of Medicine (IMSIU) in Riyadh, Kingdom of Saudi Arabia

${ }^{\square}$ Corresponding author

Imam Mohammad Ibn Saud Islamic University, College of Medicine (IMSIU), Riyadh,

Kingdom of Saudi Arabia

Email: Baialobaida@sm.imamu.edu.sa

Peer-Review History

Received: 09 December 2021

Reviewed \& Revised: 10/December/2021 to 4/January/2022

Accepted: 5 January 2022

Published: 7 January 2022

Peer-review Method

External peer-review was done through double-blind method.

URL: https://www.discoveryjournals.org/medicalscience

\section{(c) (1)}

This work is licensed under a Creative Commons Attribution 4.0 International License.

\section{Assessment of otolaryngology knowledge among primary care providers in Saudi Arabia}

\author{
Badr A Alobaida ${ }^{\circledR}$, Faisal A Alayed ${ }^{1}$, Abdullah K \\ Alrudayni ${ }^{1}$, Rakan A Alzabadin ${ }^{1}$, Sultan A Aldera ${ }^{1}$, Naif \\ I Alrajhi ${ }^{1}$, Meshal I Alfrayan ${ }^{1}$, Abdulrahman K \\ Almassari ${ }^{1}$, Feras A Alrakaf ${ }^{1}$, Fahad Z Alotaibi ${ }^{2}$
}

\begin{abstract}
Objective: This study aims to assess the knowledge and deficits of otolaryngology in primary care physicians who work at primary care centers or tertiary hospitals in Riyadh, KSA. Methods: This is a cross-sectional study conducted among residents of primary care specialties and otolaryngology residents in Riyadh, Saudi Arabia. A 10-item question with multiple-choice to assess the knowledge toward otolaryngology was given to the primary care provider by using face to face interview. Further, questions about clinical rotation in otolaryngology during medical school and residency were asked whether they participated or not. Results: A total of 253 primary care physicians took part (92 internal medicines, 79 family medicines, and 82 pediatrics) and 13 otolaryngologists, Primary care physicians who participated in clinical rotations during medical school and residency were $79.7 \%$ and $26.3 \%$, respectively. Otolaryngologists' percentage of average correct knowledge score was $(89.2 \%)$, family medicine $(62.9 \%)$, pediatrics $(55.4 \%)$, and internal medicine $(52.5 \%)$. Primary care providers who participated in a clinical rotation in otolaryngology showed significantly higher knowledge scores than those who did not participate $(p<0.001)$. Conclusion: primary care physicians had unsatisfactory ratings after examinations. Previous otolaryngology clinical rotation during residency had a positive effect on the knowledge of PCPs with their daily practice, which supports adding further clinical training in otolaryngology for primary care specialties.
\end{abstract}

Keywords: otolaryngology; Knowledge; primary care physicians; residency; assessment

\section{INTRODUCTION}

A primary care physician $(\mathrm{PCP})$ is the first doctor that the patients will face in primary care centers or hospitals, they deal with the most common cases, the Primary care services receive approximately 300 million consultations per year, and a significant portion of this number is due to Otolaryngic diseases 
(Mathie, 1997). It is estimated that 20\% of adult patient visiting general practice present with ENT problems (Griffiths, 1979), this number reaches around 50\% for the pediatric population (Hannaford et al., 2005), this shows us that it is crucial that primary care providers know how to diagnose and manage patients with otolaryngic problems in the community. The way the primary care physicians are taught to deal with patients who have otolaryngic problems is different depending on the training they received and the Exposure to otolaryngology cases is often deficient due to the shortage of otolaryngology rotations (Khan \& Saeed, 2012).

There is a gap within the current curriculum of the otolaryngology in the (PCPs) specialties, multiple studies tried to measure if PCPs were satisfied with their training in otolaryngic condition or not, according to a study performed in the United Kingdom where they asked GPs if they believe that they received adequate training in ENT rotations, $75 \%$ of them said that their training in otolaryngology is insufficient, and the same number said that they would like further training (Clamp et al., 2007). Also in another study the results showed that $90 \%$ of the emergency medicine physicians believed that their practice is getting benefit by their otolaryngology training, however $75 \%$ of the participants believed they didn't receive enough training (Sharma et al., 2006). Another study performed on 16 Canadian medical schools showed that majority of Canadian medical graduates complete their undergraduate training with low clinical experience in otolaryngology (Campisi et al., 2008).

The Saudi board for family medicine which operates under the Saudi commission for health specialties released the 2020 family medicine curriculum (SCFHS, 2020), the otolaryngology curriculum within the family medicine program tries to provide exposure to common otolaryngic conditions in screening and identifying emergencies either acute and chronic presentation in the community, the otolaryngology rotation is 4 weeks long which raises some concerns if that's considered to be sufficient considering how common are the diseases of otolaryngology.

The aim of this study is to assess the knowledge and deficits of otolaryngology in primary care physicians who work at primary care centers or tertiary hospitals in Riyadh, KSA and to determine if there is any need for further improvement to the otolaryngology curriculum among primary care physicians.

\section{MATERIALS AND METHODS}

A 10 question multiple choice exam adapted from previous literature by (Erorr et al., 2013), listed in supplemental appendix A, was administered to current residents in the following specialties : internal medicine, pediatrics, family medicine and otolaryngology, the residents were based in Saudi Arabia, Riyadh in multiple tertiary and primary care centers via face to face interview, otolaryngology residents were used as a comparison tool against primary care residents to be able to determine their adequacy, all responses were categorized according to specialty and all responses were anonymous.

The survey was divided into two parts, the first part was basic demographic characteristics such as year of study, specialty, prior clinical or medical school rotations that was undertook, the 2nd part was a 10 question multiple choice exam that covered basic anatomy knowledge and frequent conditions that primary care providers face on a day to day basis, all questions are scored from 0-10 with only having one correct answer, the responses were categorized into 4 groups: internal medicine, pediatrics, family medicine and otolaryngology, the duration of the study and data collection started from September 2020 and ended at august 2021 , answers were graded and assigned to each respective specialty.

\section{Statistical Analysis}

The data were analyzed using Statistical Packages for Social Sciences (SPSS) version 26 (Armonk, NY: IBM Corp., USA). Both descriptive and inferential statistics was conducted. A p-value cut-off point of 0.05 at $95 \%$ CI was used to determine statistical significance. In descriptive statistics, all categorical variables had been presented as numbers and percentages while all continuous variables had been summarized as mean \pm standard deviation. Fischer tests and Mann Whitney U tests had been applied for the comparison of independent variables against the dependent variable. A normality test was performed to determine the overall distribution of data by using Shapiro Wilk test.

\section{RESULTS}

Table 1 Basic demographic characteristics of the primary care physicians ${ }^{(n=266)}$

\begin{tabular}{ll}
\hline Study Data & $\mathrm{N}(\%)$ \\
\hline Year of training & \\
PGY-1 & $68(25.6 \%)$ \\
PGY-2 & $71(26.7 \%)$ \\
PGY-3 & $71(26.7 \%)$
\end{tabular}




\section{PGY-4}

Specialty

Internal medicine

Family medicine

Pediatrics

Otolaryngology

Underwent clinical rotation in otolaryngology

during medical school

Yes

No

Underwent clinical rotation in otolaryngology during residency

Yes

No
$56(21.0 \%)$

$92(34.6 \%)$

$79(29.7 \%)$

$82(30.8 \%)$

$13(04.9 \%)$

$212(79.7 \%)$

$54(20.3 \%)$

$70(26.3 \%)$

$196(73.7 \%)$

According to the statistical year book of 2020 that was released by the Saudi ministry of health (MOH) there were 852 physicians who met the inclusion criteria, 266 physicians agreed to participate in the study for a response rate of $31.2 \%$. Table 1 presented the basic demographic characteristics of the primary care physicians. Respondents constitute mostly of PGY-2 (26.7\%), PGY-3 (26.7\%) and PGY-1 (25.6\%). With regards to specialty, 34.6\% were internal medicine, 30.8\% were pediatrics and $29.7 \%$ were family medicine. The proportion of respondents who underwent clinical rotations in otolaryngology during medical school and residency were $79.7 \%$ and $26.3 \%$, respectively.

In table 2, the prevalence of respondents who correctly identified the anatomy often tonsillectomy ( $<<0.001)$, the most common causeof head and neck cancer $(\mathrm{p}=0.028)$, the treatment for sudden sensorineural hearing loss $(\mathrm{p}<0.001)$, the most common cause of stridor in an infant $(\mathrm{p}<0.001)$ and the structure of middle turbinate $(\mathrm{p}<0.001)$ were significantly more in otolaryngology residents while those who correctly identified the consequence of occluding laryngectomy stoma was more common among family medicine specialty $(\mathrm{p}=0.001)$.

Table 2 Percentage of primary care physicians that answered each question of the quiz correctly $(\mathrm{n}=266)$

\begin{tabular}{|c|c|c|c|c|c|}
\hline Question & $\begin{array}{l}I M \\
\mathrm{~N}(\%)\end{array}$ & $\begin{array}{l}F M \\
\mathrm{~N}(\%)\end{array}$ & $\begin{array}{l}\text { Pedia } \\
\mathrm{N}(\%)\end{array}$ & $\begin{array}{l}\text { Oto } \\
\mathrm{N}(\%)\end{array}$ & P-value \\
\hline Tonsil anatomy & $33(35.9 \%)$ & $26(32.9 \%)$ & $39(47.6 \%)$ & $13(100 \%)$ & $<0.001 * *$ \\
\hline Initial treatment of allergic rhinitis & $79(85.9 \%)$ & $71(89.9 \%)$ & $70(85.4 \%)$ & $13(100 \%)$ & 0.484 \\
\hline $\begin{array}{l}\text { Most common cause of asymptomatic } \\
\text { neck mass in adult }\end{array}$ & $62(67.4 \%)$ & $66(83.5 \%)$ & $67(81.7 \%)$ & $12(92.3 \%)$ & $0.028^{* *}$ \\
\hline $\begin{array}{l}\text { Initial treatment of sudden sensorineural } \\
\text { hearing loss }\end{array}$ & $15(16.3 \%)$ & $20(25.3 \%)$ & $04(04.9 \%)$ & $12(92.3 \%)$ & $<0.001^{* *}$ \\
\hline $\begin{array}{l}\text { Most common cause of stridor in an } \\
\text { infant }\end{array}$ & $48(52.2 \%)$ & $64(81.0 \%)$ & $67(81.7 \%)$ & $13(100 \%)$ & $<0.001 * *$ \\
\hline Identify the middle turbinate & $28(30.4 \%)$ & $21(26.6 \%)$ & $13(15.9 \%)$ & $12(92.3 \%)$ & $<0.001^{* *}$ \\
\hline $\begin{array}{l}\text { Identify the correct placement of } \\
\text { cricothyrotomy }\end{array}$ & $45(48.9 \%)$ & $46(58.2 \%)$ & $38(46.3 \%)$ & $10(76.9 \%)$ & 0.122 \\
\hline $\begin{array}{l}\text { Consequence of occluding laryngectomy } \\
\text { stoma }\end{array}$ & $32(34.8 \%)$ & $51(64.6 \%)$ & $43(52.4 \%)$ & $07(53.8 \%)$ & $0.001 * *$ \\
\hline Most common bacteria for otitis media & $67(72.8 \%)$ & $62(78.5 \%)$ & $58(70.7 \%)$ & 13 (100\%) & 0.090 \\
\hline $\begin{array}{l}\text { First line treatment for acute bacterial } \\
\text { rhinosinusitis }\end{array}$ & $86(93.5 \%)$ & $71(89.9 \%)$ & $72(87.8 \%)$ & $11(84.6 \%)$ & 0.436 \\
\hline
\end{tabular}

IM - Internal Medicine; FM - Family Medicine; Pedia - Pediatrics; Oto - Otolaryngology

§P-value has been calculated using Fischer Exact test.

** Significant at $\mathrm{p}<0.05$ level. 
Figure 1 depicted the percentages for the overall correct answer of the primary care physicians. It can be observed that the overall familiarity about the first-line treatment for acute bacterial rhinosinusitis has the highest correct knowledge (90.2\%), followed by the first-line treatment of nasal obstruction or clear rhinorrhea (87.6\%) and the most common cause of head and neck cancer $(77.8 \%)$ while familiarity about the management of sudden sensorineural hearing loss has the least correct knowledge identified by the primary care physicians (19.2\%).

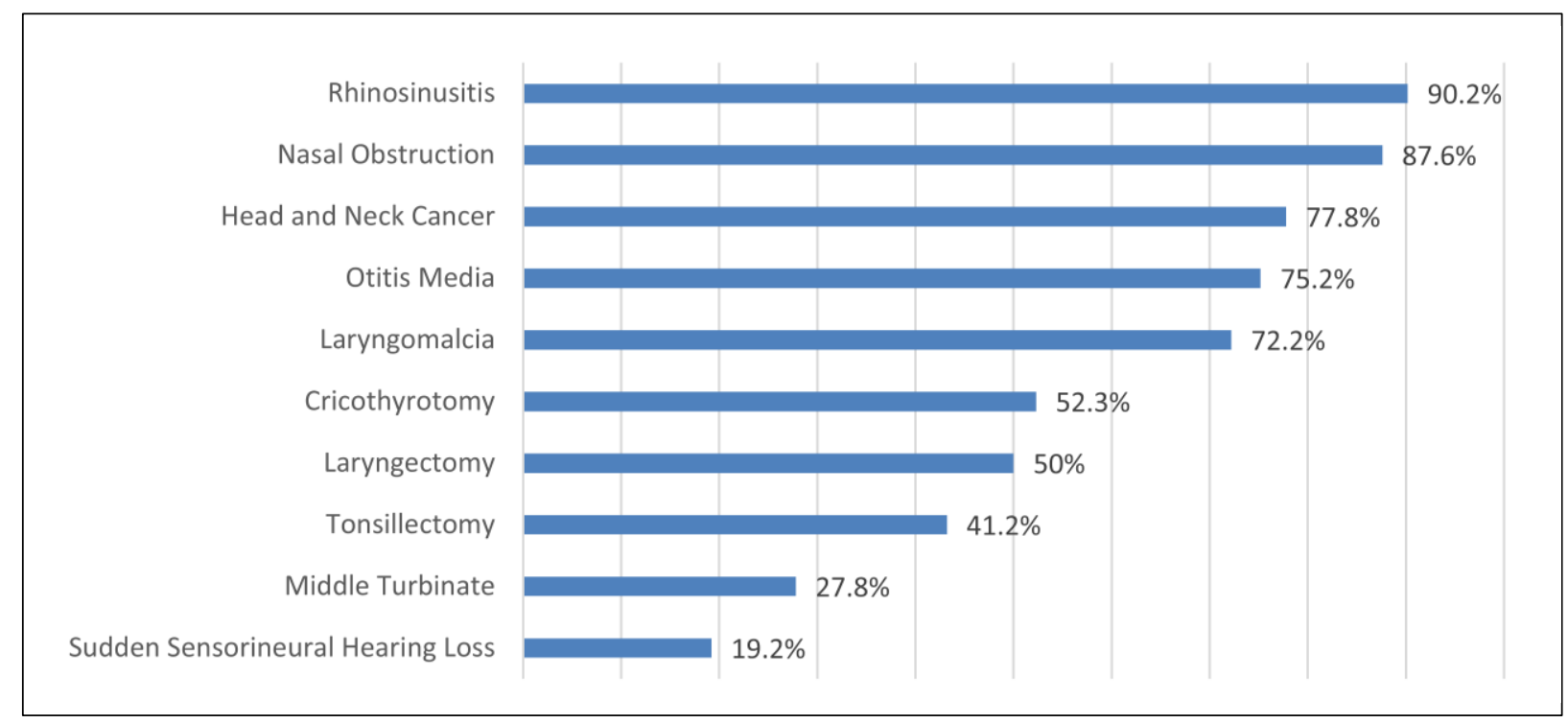

Figure 1 Percentages of the overall correct answer of the primary care physicians

Table 3 Assessment of knowledge based on $\operatorname{cohort}^{(\mathrm{n}=266)}$

\begin{tabular}{ll}
\hline Specialty & Mean \pm SD \\
\hline Internal medicine & $5.25 \pm 1.50$ \\
PGY-1 & $5.43 \pm 1.42$ \\
PGY-2 & $5.00 \pm 1.56$ \\
PGY-3 & $5.43 \pm 1.59$ \\
PGY-4 & $5.08 \pm 1.44$ \\
Family medicine & $6.29 \pm 1.63$ \\
PGY-1 & $5.82 \pm 1.54$ \\
PGY-2 & $6.19 \pm 1.69$ \\
PGY-3 & $6.61 \pm 1.67$ \\
PGY-4 & $6.13 \pm 1.54$ \\
Pediatrics & $5.54 \pm 1.23$ \\
PGY-1 & $5.39 \pm 1.47$ \\
PGY-2 & $5.70 \pm 0.92$ \\
PGY-3 & $5.94 \pm 1.18$ \\
PGY-4 & $5.22 \pm 1.11$ \\
Otolaryngology & $8.92 \pm 1.19$ \\
PGY-1 & $6.00 \pm--$ \\
PGY-2 & $9.00 \pm 0.00$ \\
PGY-3 & $9.00 \pm--$ \\
PGY-4 & $9.22 \pm 0.97$ \\
\hline
\end{tabular}




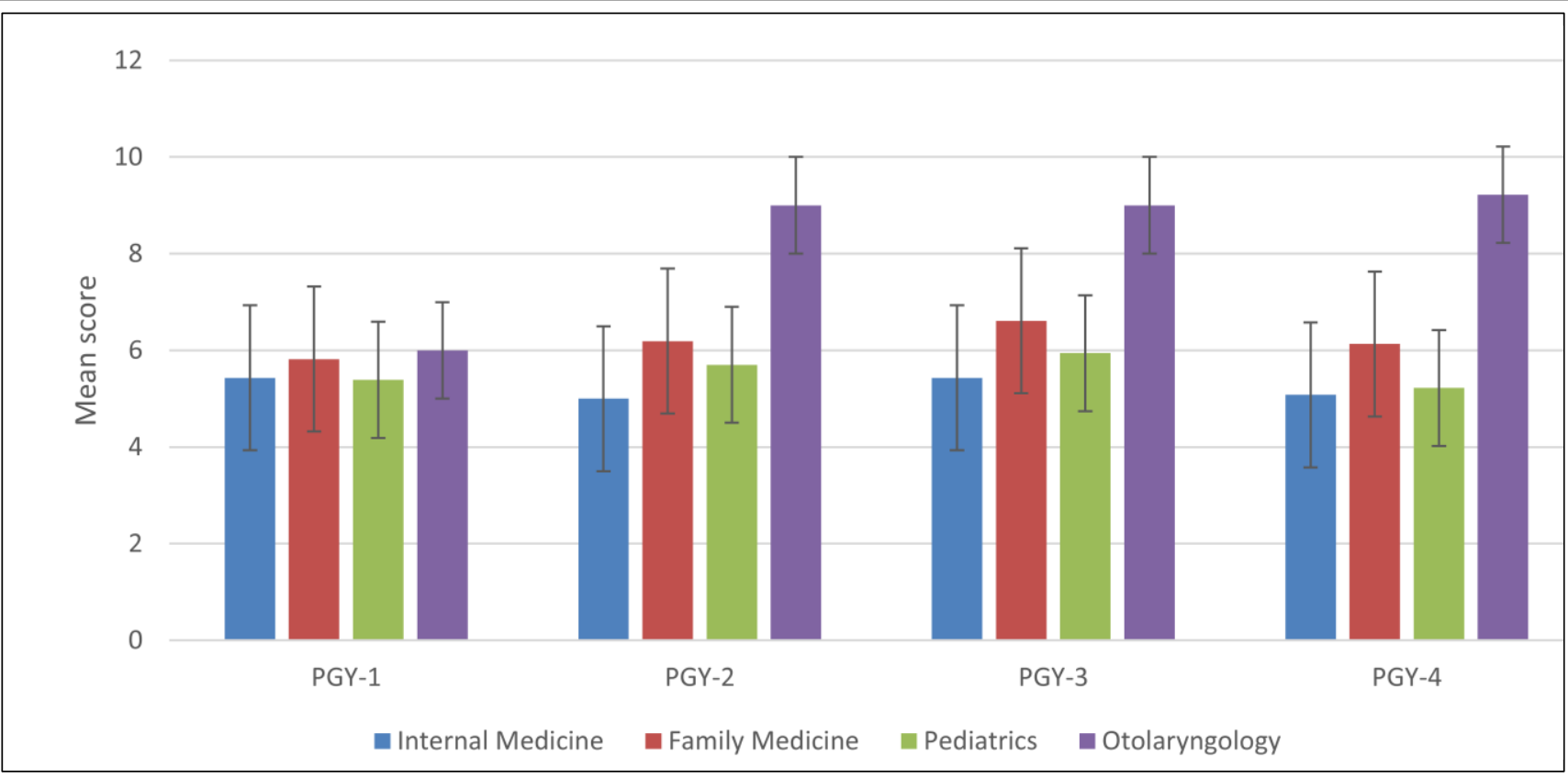

Figure 2 Assessment results compared to year of training

Table 3 showed the assessment of knowledge according to specialties. It was revealed that the mean knowledge score of Internal medicine specialty was 5.25 (SD 1.50). When stratified with the level of training, PGY-1 has the highest mean knowledge score with 5.43and PGY-3 (mean: 5.43). Furthermore, the mean knowledge score of family medicine specialty was 6.29 (SD 1.63 ), when stratified with the level of training, PGY-3 has the highest mean with 6.61, followed by PGY-2 (mean: 6.19). With regards to pediatrics specialty, the mean knowledge score of pediatrics was 5.54 (SD 1.23) with PGY-3 having the highest mean knowledge score (mean: 5.94), followed by PGY-2 (mean: 5.70). Finally, with regards to otolaryngology specialty, the mean knowledge score was 8.92 (SD 1.19) with PGY4 having the highest mean knowledge score (mean 9.22) (Figure 2).

Table 4 Knowledge assessment results according to clinical rotations in otolaryngology $\mathrm{y}^{(\mathrm{n}=266)}$

\begin{tabular}{llc}
\hline Variables & $\begin{array}{l}\text { Knowledge score } \\
\text { Mean } \pm \text { SD }\end{array}$ & P-value \\
\hline Clinical rotation in otolaryngology during medical school & & \\
Yes & $6.00 \pm 1.48$ & 0.339 \\
No & $5.78 \pm 1.67$ & \\
Clinical rotation in otolaryngology during residency & & \\
Yes & $6.44 \pm 1.58$ & \\
No & $5.78 \pm 1.47$ & \\
\$ P-value has been calculated using Mann Whitney U test. & & \\
** Significant at $\mathrm{p}<0.05$ level. &
\end{tabular}

In Table 4, the mean knowledge score of those who underwent clinical rotation in otolaryngology during residency was statistically significantly higher than those who did not undergo clinical rotation $(p<0.001)$ while the difference in the knowledge score for those who underwent and did not undergo clinical rotation during medical school was not significantly different $(\mathrm{p}=0.339)$.

\section{DISCUSSION}

The present study attempted to evaluate the knowledge of primary care physicians regarding otolaryngology basic theories and enumerate which topics they have deficiencies. We viewed that this is the first study in Saudi Arabia that measures PCPs' familiarity with otolaryngology. The findings of this would add to the existing pieces of evidence that could shed more light on the readiness of PCPs in encountering otolaryngologic cases in primary care settings. In this study, the overall correct knowledge of primary care physicians regarding otolaryngology was (56.9\%), of them, the knowledge was higher among family medicine (62.9\%), followed by pediatrics $(55.4 \%)$ and the least knowledge was identified among internal medicine residents (52.5\%) the 
otolaryngology resident group scored an average of $(89.2 \%)$. Consistently, several published papers in the United States reported a better knowledge among otolaryngologist residents than other specialties. For example, (Erorr et al., 2013) reported that the overall knowledge of otolaryngologist residents regarding the subject was $92 \%$, while $56 \%$ for non-otolaryngologists and $48 \%$ for medical students.

Another study conducted by (O'Brien et al., 2018), indicated that the otolaryngology cohort has an average score of 93\% and the rest of the specialties scored $56 \%$. They further indicated that there were significant knowledge gaps among non-otolaryngologists in the diagnosis and treatment of basic otolaryngologic conditions which were consistent with our reports. However, a study published by (Hsieh et al., 2020), during pre-lecture determined that the average score of otolaryngologist physicians was $97.8 \%$ while non-otolaryngologist was 55.1\%. However, after 3-month post-lecture, all non-otolaryngology physicians improved scores significantly from $58.3 \%$ to $86.5 \%$. This indicates that through an instructional lecture, the deficits in the knowledge can be narrowed and improved upon. Authors further suggested that a periodic assessment of basic principles for non-otolaryngology physicians could be a better method to ensure the appropriate treatment of patients with otolaryngologic disorders.

The deficiency in PCPs' knowledge regarding otolaryngology stemmed out from the specific item indicated in the knowledge questionnaire. For instance, in our study, otolaryngology residents showed poor knowledge about what cause of occlusion of a patient's laryngectomy stoma, as only $53.8 \%$ of them were able to identify the correct answer which is asphyxiation ( $\mathrm{p}=0.001$ ) while on the other hand, pediatricians exhibited a lack of knowledge regarding the initial treatment of sudden sensorineural hearing loss as only $4.9 \%$ able to identify the correct answer $(\mathrm{p}<0.001)$, they also demonstrated lack of knowledge about appropriate structure of middle turbinate $(\mathrm{p}<0.001)$ and the correct placement of cricothyrotomy $(46.3 \%)$. For family physicians, they showed a lack of familiarity with regards to the anatomy of tonsillectomy $(p<0.001)$ whereas for internal medicine they exhibited poor knowledge regarding the treatment of sudden sensorineural hearing loss $(\mathrm{p}<0.001)$ and the most common cause of stridor in an infant $(\mathrm{p}<0.001)$. Various papers reported conflicting reports regarding the deficiencies in some areas related to otolaryngology-related issues specifically among non-otolaryngologists.

For instance, (Erorr et al., 2013) found out that in the issue of the middle turbinate, only 18\% were correct among nonotolaryngologists while regarding the occlusion of laryngectomy stoma, only $20 \%$ were able to identify the correct answer. In Saudi Arabia (Al-Khatib et al., 2016), most physicians showed better perceptions regarding the otolaryngology specialty. According to the report, nearly all physicians knew that otolaryngologists were experienced in dealing with pharyngeal lesions, hoarseness symptoms, managing foreign body ingestion, and performing tracheostomies.

Experience in otolaryngology clinical rotations is tantamount to knowledge improvement. In this study, the majority of PCPs had participated the clinical rotations and we further noticed that PCPs who participated in the clinical rotation during residency had significantly better knowledge compared to those who didnt participate $(\mathrm{p}<0.001)$ which was similarly reported by $\left(\mathrm{O}^{\prime}\right.$ Brien et al., 2018). Furthermore, its reported that due to the deficiency in the knowledge of pediatric residents regarding otolaryngologists, (Fabian, 2005) extrapolated that all pediatric program directors pursue the need for teaching by an otolaryngologist for pediatric residents which required further knowledge about airway problems (emergencies, stridor, tracheotomy), ear diseases, hearing loss and sinus issues.

The overall outcome of this study supported the findings of literature regarding the significant gaps in the knowledge such as (Hu et al., 2012) noted that due to the low level of otolaryngology knowledge among PCPs attending an otolaryngology update course the need for periodic education is imperative among residents where medical educators share the responsibility of nurturing PCPs to provide high quality, current otolaryngology care.

\section{CONCLUSION}

Although knowledge of otolaryngology residents seems adequate, however, the primary care physicians had unsatisfactory ratings after examinations. Previous otolaryngology clinical rotation during residency had a positive effect on the knowledge of PCPs with their daily practice. It is necessary to improve the knowledge of primary care physicians regarding otolaryngology. Since a great proportion of emergency and primary care cases were due to head and neck complaints, the importance of having a good background and education about the basic concept of otolaryngology is vital. We also emphasized the need for more otolaryngology curriculum during medical education as this will be beneficial during their practice whenever their encounter complaints of otolaryngologic problems.

\section{Acknowledgments}

The authors thank the participants who contributed to the sample and gave consent to be a part of this research. 


\section{Ethical approval}

IRB exemption was obtained from Imam Mohammad Ibn Saud Islamic university ethical committee project number (68-2020) at 1/9/2020, registration: HAPO-01-R-011.

\section{Contribution statement}

BAO and FAR wrote the literature review and conducted the research and conceived the presented idea, The introduction was written by MIF and NIR and they helped in planning the research and writing the draft version, AKM and AKR wrote the methodology part in the paper and took the lead in writing the statistical analysis FAA and SAD both participated in Designing the study and providing the research material also they conducted the final revision of the paper, RAZ wrote the conclusion and reviewed the manuscript. All authors carried out the interpretation of the results and in writing the discussion. Dr FZO supervised all the finding of the project. All authors have reviewed and approved the final form of the paper to be published.

\section{Funding}

The study did not receive any external funding

\section{Conflict of interests}

The authors declare that there are no conflicts of interests.

\section{Data and materials availability}

All data associated with this study are present in the paper.

\section{REFERENCES AND NOTES}

1. Al-Khatib T, Al-Asmari B, Al-Maghrabi F, Al-Sheikah M, ElDeek B. The perception of otolaryngology: Head and neck surgery speciality among physicians at a tertiary care hospital. J health specialties 2016; 4(3), 190-190.

2. Campisi P, Asaria J, Brown D. Undergraduate otolaryngology education in Canadian medical schools. Laryngoscope 2008; 118(11), 1941-1950. doi: 10.1097/MLG.0b013e31818208e7

3. Clamp PJ, Gunasekaran S, Pothier DD, Saunders MW. ENT in general practice: training, experience and referral rates. J Laryngol Otol 2007; 121(6), 580-583. doi: 10.1017/S0022215106003495

4. Error ME, Wilson KF, Ward PD, Gale DC, Meier JD. Assessment of otolaryngic knowledge in primary care residents. Otolaryngol. Head Neck Surg 2013; 148(3), 420424.d oi: 10.1177/0194599812472314

5. Fabian MC. Deficiencies of cross-training between pediatrics and otolaryngology. Int J Pediatr 2005; 69(8), 1043-1046 doi: 10.1016/j.ijporl.2005.03.029

6. Griffiths E. Incidence of ENT problems in general practice. J R Soc Med 1979; 72.10: 740-742.

7. Hannaford PC, Simpson JA, Bisset AF, Davis A, McKerrow $\mathrm{W}$, Mills R. The prevalence of ear, nose and throat problems in the community: results from a national cross-sectional postal survey in Scotland. Fam 2005; 22(3), 227-233. doi: 10.1093/fampra/cmi004

8. Hsieh TY, Timbang L, Kuhn M, Brodie H, Squires L. Assessment of tracheostomy and laryngectomy knowledge among non-otolaryngology physicians. Ann Otol Rhinol
Laryngol 2020; 129(2), 115-121. doi: 10.1177/0003489419877 198

9. Hu A, Sardesai MG Meyer TK. A need for otolaryngology education among primary care providers. Med Educ Online 2012; 17(1), 17350. doi: 10.3402/meo.v17i0.17350

10. Khan MM, Saeed SR. Provision of undergraduate otorhinolaryngology teaching within General Medical Council approved UK medical schools: what is current practice?. J Laryngol Otol 2012; 126(4), 340-344. doi: 10.1017/S0022215111003379

11. Mathie T. The primary care workforce crisis: a time for decisive action. Br J Gen Pract 1997; 47(414), 3.

12. O'Brien DC, Squires LD, Robinson AD, Ramadan H, Diaz R. A multicenter, cross-sectional assessment of otolaryngology knowledge among primary care trainees. Ann Otol Rhinol Laryngol 2018; 127(9), 631-636. doi: 10.1177/000348941878 4615

13. Saudi commission for health specialties. Saudi Board for Family Medicine Curriculum 2020; pp. 22-72.

14. Sharma A, Machen K, Clarke B, Howard D. Is undergraduate otorhinolaryngology teaching relevant to junior doctors working in accident and emergency departments?. J Laryngol Otol 2006; 120(11), 949-951. doi: $10.1017 /$ S0022215106002246 